\title{
Observations de comètes à l'Observatoire d'Alger.
}

Positions de la Comète rgrab (Zlatinsky) obtenues avec l'équatorial photographique, par M. Gonnessiat.

[Mesures des clichés et calculs avec le concours de $\mathrm{M}^{\text {me }}$ Baldet.]

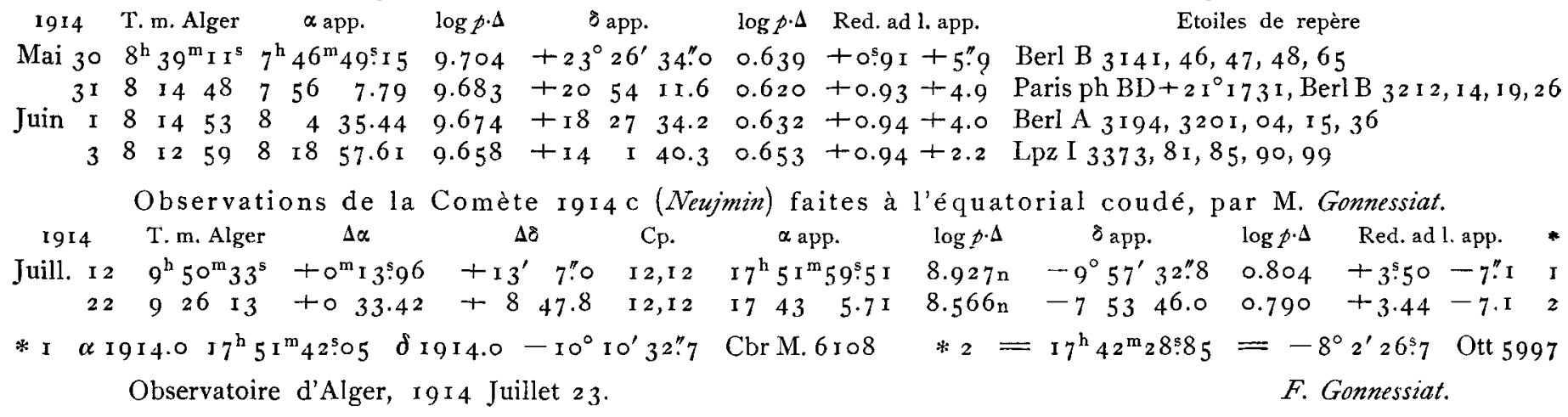

\section{Beobachtungen Kleiner Planeten auf der Königstuhl=Sternwarte.}

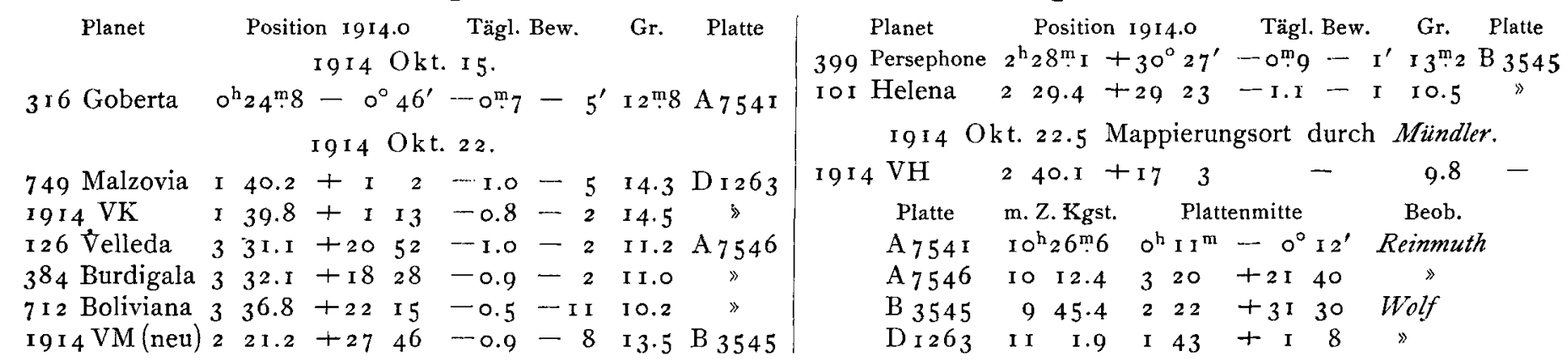

Von den beiden I9I 4 Oktober I 5 auf Platte D I 259 aufgenommenen Objekten (vgl. A. N. I99.238) ist das erste nunmehr als mit $1914 \mathrm{VK}$, das zweite als mit 749 Malzovia identisch nachweisbar.

Heidelberg; I 9 I 4 'Okt. 24.

M. Wolf.

\section{Notiz zu zwei Sternen $\mathbf{8}^{\mathrm{m}} \mathbf{5}$, die in der BD fehlen (vgl. A. N. 4757).}

$\mathrm{Zu}$ der Notiz des Herrn Graff in A. N. 4757 ist nach den Originalen der BD folgendes hinzuzufügen.

Über den Ort des Sternes Meyer Nr. $4_{2} 8^{\mathrm{m}} \cdot 5 \mathrm{I}^{\mathrm{h}} 2 \mathrm{I}^{\mathrm{m}}{ }_{1} 4^{\mathrm{s}}$. $+20^{\circ} 6{ }_{4}^{\prime}(1855)$ sind gegangen die Sucherzonen 728 , I 855 Sept. 10 , und 753 , I 855 Okt. $3 \mathrm{I}$, ferner die Revisionszone am Fünffüßer $221, I_{5} 8$ April 20 . In keiner dieser drei Zonen ist am angegebenen Ort ein Stern beobachtet.

Bonn, I9I 4 Sept. 29.
Über den Ort des Graffschen Sternes $8^{\mathrm{m}} \cdot 58^{\mathrm{h}} \mathrm{I}^{\mathrm{ml}} 35^{\mathrm{s}} \cdot 6$ $+40^{\circ} 38^{\prime} \cdot 3$ ( I 855 ) sind gegangen die Sucherzonen I I 9 I, I 857 Febr. 25. I 20 I, I 857 März I 5, und I 809 , I 859 Febr. 3. In allen drei Zonen fehlt der Stern, während der I $4{ }^{\text {s }}$ folgende o'.7 nördliche Stern $+40^{\circ} 203 \mathrm{I}$ als $8 \cdot 5,8^{\mathrm{m}}$. 0 und $9^{\mathrm{m}} \cdot$ o beobachtet ist. Es ist hiernach anzunehmen, daß der Graffsche Stern in diesen Epochen schwächer als neunter Größe gewesen ist.

Neunter Jupiterstrabant. Nach dem am 23. Oktober bei der Redaktion eingetroffenen Bulletin 560 des Harvard College Observatory, welches am I2. September I9 I4 ausgegeben ist, hat die Bahnberechnung des am 2 I. Juli I9I4 bei Jupiter von ihm aufgefundenen Objektes (vgl. A. N. 198.487) S. B. Nicholson zur Bestätigung der Annahme geführt, daß es sich um einen neuen Jupiterstrabanten handelt.

Inhalt zu Nr. 4768. G. Witt. Nomogramme der Gaußschen Gleichung. 257. - F. E. Ross. On the night error, and possible short period terms in the latitude variation. 259. - F. Hayn. Die Rotationselemente des Mondes und der definitive Ort von Mösting A. 261. - F. Angelitti. Adhuc pauca de principio medii arithmetici. 263. - R. Suppantschitsch. Rursus de principio medii arithmetici. 265. - E.S. Manson. Measurements of positions of asteroids. 269. - B. H. Dawson. Observations of Comet 1914 a (Kritzinger). 269. - F. Gonnessiat. Observations de comètes à l'Observatoire d'Alger. 271. - M. Wolf. Beobachtungen Kleiner Planeten auf der Königstubl-Sternwarte. 27I. - F.'Küstner. Notiz zu zwei Sternen 8.5 , die in der BD fehlen (vgl. A. N. 4757). 27I. - Neunter Jupiterstrabant. 27 I. 